\title{
Congenital pseudoarthrosis of clavicula
}

\author{
Ahmet Korkmaz ${ }^{1}$, Ayşe Yavuz Aydoğdu² \\ ${ }^{1}$ Clinic of Ortoapedics, Lüleburgaz Private Derman Hospital, Kırklareli, Turkey \\ ${ }^{2}$ Clinic of Pediatrics, Lüleburgaz Private Derman Hospital, Kırklareli, Turkey
}

\begin{abstract}
Right clavicula fracture was found in a male patient who was brought to our outpatient clinic at the age of 7 days with a complaint of swelling on the right clavicula. The patient had no history of difficult delivery or resuscitation. He was born at term by spontaneous vaginal delivery with a birth weight of $3340 \mathrm{~g}$ from the first pregnancy of his mother and there was no consanguinity between the parents. Orthopaedic examination repeated at the age of 2 months revealed pathological movement in the middle of the clavicula and a swelling with a diameter of $1 \mathrm{~cm}$. There was no tenderness. Asymmetry was noted between the shoulders, but range of motion was normal in both shoulders. On radiographic examination, it was observed that the proximal and distal fragment in the middle region of the clavicula were displaced by $1 \mathrm{~cm}$ and there was no callus. It was noted that the medial end of the distal fragment was blunt and sclerotic. There was no other pathology related with the musculosketal system. Examination of the other systems was found to be normal. Thus, a diagnosis of congenital clavicula pseudoarthrosis was made. This condition is rare and there are less than 200 cases in the literature. Congenital clavicula pseudoarthrosis almost always develops on the right side. Pseudoarthrosis was also on the right side in our patient. It is rarely bilateral (10\%). It rarely occurs on the left clavicula and is usually associated with dextrocardia. Familial association is present in very few of the reported cases, but there is no genetic background. It is rarely diagnosed in the neonatal period. The diagnosis was made in the neonatal period in our patient. Shoulder functions are not affected, but painful deformity, cosmetic problems or thoracic outlet syndrome may be observed in the adolescence and afterwards. (Türk Ped Arş 2014; 49: 261-3)
\end{abstract}

Key words: Baby, congenital, clavicula, pseudoarthrosis, radiography

\section{Introduction}

Congenital clavicula pseudoarthrosis is a rare condition. Congenital clavicula pseudoarthrosis whic affects both genders equally almost always develops in the right side and is rarely bilateral (10\%) (1). In the differential diagnosis of congenital clavicula pseudoarthrosis, neonatal fracture and cleidocranial disosytosis are considered. It is differentiated from acute neaonatal fractures with absence of birth trauma and absence of early excessive callus (1). It is differentiated from cleidocranial disosytosis with defective appearance in the clavicula and absence of malformation in the other bones on radiography (1). The actual etiology of this condition which is thought to arise from defect of fusion of two primary ossification centers of the clavicula is not known exactly. On radiographies, the sternal part is larger and is observed over the acromial part $(1,2)$.

\section{Case}

A 7-day old male patient presented to our pediatric outpatient clinic with a complaint of swelling on the right clavicula. The patient had no history of difficult delivery or resuscitation. The patient was born by normal spontaneous delivery with a birth weight of $3340 \mathrm{~g}$. It was the first pregnancy of the patient's mother and there was no consanguineous marriage between the parents.

On orthopaedic examination of the patient, clavicula fracture was considered. Shoulder-arm strap was made. It was thought that a one-week application would be sufficient. When the patient presented for a follow-up visit after 20 days, the family stated that there was movement on the clavicula of the baby. Delayed bone union was considered. The patient was asked to come

Address for Correspondence: Ayşe Yavuz Aydoğdu, Clinic of Pediatrics, Lüleburgaz Private Derman Hospital, Krrklareli, Turkey.

E-mail: mdrayaydogdu@yahoo.com

Received: 12.11.2012 Accepted: 06.03.2013

(C) Copyright 2014 by Turkish Pediatric Association - Available online at www.turkpediatriarsivi.com 
back one month later for a follow-up visit. On orthopaedic examination, a mobile swelling with a diameter of $1 \mathrm{~cm}$ was present in the middle of the clavicula. There was no ternderness. On radiography, it was observed that the proximal and distal parts in the middle region of the clavicula changed place for $1 \mathrm{~cm}$ and there was no callus. It was observed that the medial end of the distal part was blunted and sclerotic (Figure 1, 2). Thus, clavicula pseudoarthrosis was considered. Asymmetry between the shoulders was noted. However, rage of joint motion in both shoulders was normal. Other systemic findings were evaluated to be normal.

General physical examination: at the second month, weight: $5700 \mathrm{~g}(25 \mathrm{p})$, height: $57 \mathrm{~cm}$ (50 p), head circumference: 40.3 $\mathrm{cm}(50-75 \mathrm{p})$. General status was well, the anterior fontanelle had a size of $2 \times 1.5 \mathrm{~cm}$. The shape of the head was normal. Examination of the cardiovascular system was normal; no additional sound or murmur was heard. Respiratory sounds were normal, abdominal examination was normal, there was no hepatosplenomegaly. The patient had male external genitalia, the testicles were descended and there was no hydrocele. Examination of the musculoskeletal system revealed no finding suggesting pathology. There were no "Cafe-au-lait" spots. Neurological examination was found to be normal.

A diagnosis of congenital pseudoarthrosis was made in the patient who did not have pathology in the cervical vertebrae, dextrocardia, findings suggesting cleidocranial disosytosis and skin lesions suggesting neurofibromatosis.

Surgical indication was not considered in the patient whose joint range of motion was normal. He was followed-up.

\section{Discussion}

This is a rare condition. In the literature, less than 200 cases have been reported. It was reported by Fitzwilliams for the first time in 1910 (3). Congenital pseudoarthrosis almost always oc-

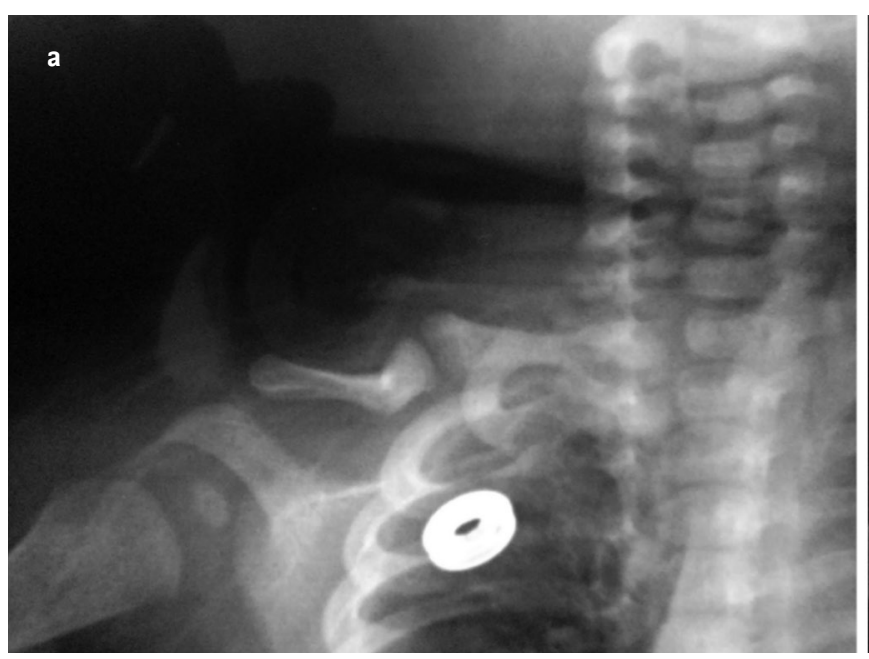

curs in the right side. In our patient, pseudoarthrosis was also on the right side. It rarely occurs bilaterally $(10 \%)(1,4)$. It rarely occurs in the left side alone and is generally associated with dextrocardia (5). Familial association is present in a small portion of the cases reported $(1,6)$. However, there is no genetic predisposition (5). It affects both genders equally (1). The medial segment of the clavicula which is larger is placed over the lateral segment which is smaller $(2,7)$. It is rarely diagnosed in the neonatal period. Our patient was diagnosed in the neonatal period. Shoulder functions are not affected, but painful malformation and cosmetic problems may be observed. Thoracic outlet syndrome is characterized with venous dilatation and blue discolouration in the arm (5).

The clavicula is the first embrionic/fetal bone which ossifies primarily (1). The clavicula can be differentiated in an embrio with a lenght of $11 \mathrm{~mm}$. In the $15 \mathrm{~mm}$ stage, it is observed as two different anterior cartilages. In the $17 \mathrm{~mm}$ stage $\left(5-7^{\text {th }}\right.$ gestational week), different ossification centers appear in the center of both anterior-cartilages. In the following stage, the close ends of the pre-cartilage masses fuse with each other. The combination line is observed in the $18-19 \mathrm{~mm}$ stage. According to Fawcett (8), lack of ossification of the anterior-cartilage bridge which connects the sternal and acromial part in the $19 \mathrm{~mm}$ stage causes to clavicula pseudoarthrosis. This hypothesis can not explain why the the cases mostly occur on the right side. According to the hypothesis of Lloyd-Roberts et al. (9), the right subclavian artery which is localized higher compared to the left one compresses the developing clavicula and leads to this condition. The increased probability of dextrocardia in patients with congenital clavicula pseudoarthrosis on the left side supports this hypothesis. It has been thought that the cervical vertebrae which are found on the right side and cause to arterial compression may efficient in the same way like the right subclavian artery.

In the differential diagnosis, cleidocranial disosytosis is considered. It is a familial disease of the skeletal system. It has

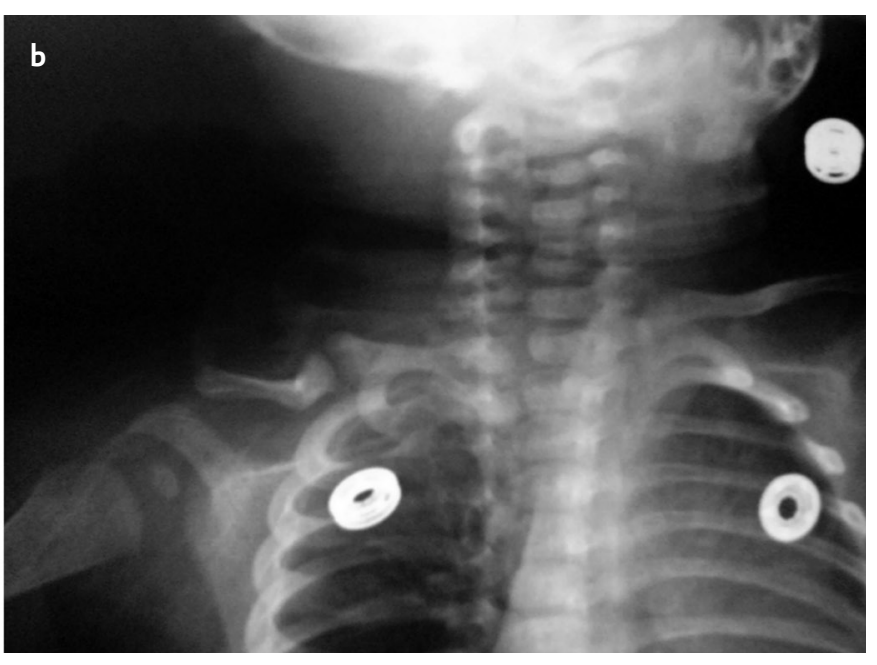

Figure 1. a, b. Antero-posterior plain radiography 
autosomal dominant inheritance. Spontaneous mutation occurs with a rate of $16-35 \%$. It may involve many bones. It is thought that there is problem in ossification of membraneous bones. Most of the patients have defect in the clavicula or absence of clavicula. The defect in the clavicula is generally bilateral (7). The head is large. The fontanelles and sutures are large. The teeth are irregular and closely spaced. Defect in the cranial bones, small facial bones, scoliosis, abnormal ephyphises in the bones of the hands and feet, defects in the pelvic ring and large symphysis pubis may be observed $(4,7)$.

It is important to differentiate congenital clavicula pseudoarthrosis from birth trauma. Formation of callus is very rapid in birth trauma. Most of the fractures casued by birth trauma are greenstick fractures (there is no dislocation). The most important point is that a considerable amount of callus is observed in post-traumatic pseudoarhtrosis, while there is no callus on radiography in congenital cases (7).

The patients generally want to be operated because of cosmetic reasons. However, clinical follow-up is also an option in asymptomatic patients who are not affected cosmetically and who have no functional limitation. Protective approach is recommended (6). In surgical treatment, resection, bone graft and osteosynthesis are performed. Complications including sepsis, lack of bone union and brachial plexus injury have been reported after surgery (1). Surgical treatment is generally performed at about the age of 2-4 years. After the age of 8 years the anatomy of the lesion makes application of bone graft difficult (2).

Informed Consent: Written informed consent was obtained from patient's parents.

Peer-review: Externally peer-reviewed.
Author Contributions: Concept - A.Y.A., K.A.; Funding - A.Y.A., A.K.; Data Collection and/or Processing - A.Y.A., A.K.; Literature review A.Y.A., A.K.; Writer - A.Y.A., A.K.

Acknowledgements: Thanks to Erdem Hilmi Küçükköse, Gürkan Gören and Pediatrician Mesut Aydoğdu for help.

Conflict of Interest: No conflict of interest was declared by the authors.

Financial Disclosure: The authors declared that this study has received no financial support.

\section{References}

1. Akman YE, Doğan A, Üzümcügil O, Azar N. Congenital pseudarthrosis of the clavicle in two siblings. Acta Orthop Traumatol Turc 2008; 42: 377-81. [CrossRef]

2. Alldred AJ. Congenital pseudoarthrosis of clavicle. J Bone Joint Surg (Br) 1963; 45: 312-9.

3. Fitzwilliams D. Hereditary cranio-cleido-dysostosis. With a review of all the published cases of the disease. Lancet 1910; 2: 1466-75. [CrossRef]

4. Brévaut-Malaty V, Guillaume JM. Neonatal diagnosis of congenital pseudarthrosis of the clavicle. Pediatr Radiol 2009; 39: 1376. [CrossRef]

5. Currarino G, Herring JA. Congenital pseudoarthrosis of clavicle. Pediatr Radiol 2009; 39: 1343-9. [CrossRef]

6. Kołodziej L, Bohatyrewicz A, Kotrych D. Congenital pseudoarthrosis of the clavicle: is operative treatment necessary? A report of four cases and literature review. Chir Narzadow Ruchu Ortop Pol 2008; 73: 277-80.

7. Wall JJ, San Jose MD. Congenital pseudoarthrosis of clavicle. J Bone Joint Surg (Br) 1970; 52: 1003-9.

8. Fawcett $J$. The development and ossification of the human clavicle. J Anat Physiol 1913; 47: 225.

9. Lioyd Roberts GC, Apley AG, Owen R. Reflections upon the aetiology of congenital pseudoarthrosis of clavicle. With a note on cranio-cleido dysostosis. J Bone Joint Surg (Br) 1975; 57: 24-9. 